\title{
Zingerone Attenuates Methotrexate-Induced Hepatotoxicity in Rats
}

\author{
Mehdi Goudarzi ${ }^{1}$, Zahra Basir ${ }^{2}$, Alireza Malayeri ${ }^{1}$, Ali Nesari ${ }^{1}$ and Narjes Zaeemzadeh ${ }^{3,{ }^{*}}$ \\ ${ }^{1}$ Medicinal Plant Research Center, Ahvaz Jundishapur University of Medical Sciences, Ahvaz, Iran \\ ${ }^{2}$ Department of Basic Sciences, Faculty of Veterinary Medicine, Shahid Chamran University of Ahvaz, Ahvaz, Iran \\ ${ }^{3}$ Department of Pharmacology, Ahvaz Jundishapur University of Medical Sciences, Ahvaz, Iran \\ "Corresponding author: Department of Pharmacology, Ahvaz Jundishapur University of Medical Sciences, Ahvaz, Iran. Email: zaeemzadehn@gmail.com
}

Received 2021 August 15; Revised 2021 October 08; Accepted 2021 October 19.

\begin{abstract}
Background: Methotrexate (MTX) is mainly used for the chemotherapy of different types of malignancy and some autoimmune diseases like rheumatoid arthritis and inflammatory bowel disease. The MTX application is limited by its severe side effects, including several types of hepatic injury.

Objectives: In this study, we decided to evaluate if zingerone (the main constituent of ginger) can reduce the hepatic side effects of MTX.

Methods: Thirty-five rats were divided into five groups: Control group receiving normal saline (N/S), once daily, by gavage, for 10 days, and N/S intraperitoneally (i.p.), a single dose on the ninth day; Methotrexate (MTX) group receiving N/S, once daily, by gavage, for 10 days, and MTX (i.p.), a single dose (20 mg/kg) on the ninth day; Groups 3 (ZG25), 4 (ZG50), and 5 (ZG100) receiving zingerone $(25,50$, and $100 \mathrm{mg} / \mathrm{kg}$, respectively), once daily, by gavage, for 10 days, and MTX (i.p.), a single dose (20 mg/kg) on the ninth day. Results: The results showed a significant decrease in serum AST, ALT, and ALP, as well as the hepatic content of MDA, NO, PC, TNF- $\alpha$, and IL-1 $\beta$, in the ZG groups compared with the MTX group. The activity of SOD, CAT, and GPX, as well as the hepatic content of GSH, showed a significant increase in the ZG groups compared with the MTX group. Histopathological improvement in the hepatic tissue of ZG groups compared with the MTX group confirmed all other findings.

Conclusions: It is concluded that zingerone can improve hepatic injury induced by MTX in rats regarding the redox system features, inflammation, and histological changes. This can make humans hopeful for using Ginger in the future for attenuating the hepatic side effects of MTX when used chronically.
\end{abstract}

Keywords: Methotrexate, Oxidative Stress, Zingerone, Hepatic Injury

\section{Background}

Methotrexate (MTX), is an antagonist of folic acid, and a key drug for the treatment of different types of cancer (1). Also, MTX is used in many other diseases like different types of arthritis, some kinds of leukemia, and inflammatory bowel disease (Crohn's disease and ulcerative colitis) (2). However, MTX side-effects limit its application, with hepatic complications (hepatitis, cirrhosis, hepatic fibrosis, and hepatocellular necrosis) being the most severe (1).

The mechanism responsible for MTX hepatotoxicity is not clearly defined. Some researchers mention that it is associated with oxidative stress and enhanced inflammatory processes (3). They proposed that MTX results in lipid peroxidation and also lowers the levels of antioxidant enzymes like catalase (CAT), glutathione peroxidase (GPx), superoxide dismutase(SOD), and glutathione reductase(GR), indicating oxidative stress and disturbing the antioxidant enzyme defense systems $(1,4)$. There are documents that prove in the processes of hepatotoxicity induced by MTX, malondialdehyde (MDA, an indicator of enhanced lipid peroxidation) increases $(3,5)$ and reduced glutathione (GSH, a defender in the redox system) decreases (4). Another possible mechanism for hepatic injury by MTX is that MTX can increase the tissue levels of NO (6), and NO can consequently induce cell apoptosis (7). There are also studies that confirm the role of increased production of proinflammatory cytokines in the pathogenesis of liver injury in MTX-treated rats $(3,5,6)$. Besides, MTX hepatotoxicity, like any kind of hepatic injury, can increase hepatic enzymes, including alanine aminotransferase (ALT) and aspartate aminotransferase (AST) $(3,5,8)$.

Ginger (Zingiber officinale Roscoe, family: Zingiberaceae) is a plant that produces one of the most common spices used all over the world. It has a pungent odor and taste and adds a special flavor to edibles (9). Zingerone is present in a significant amount in Ginger and is known to have potent pharmacological activities (10). Ginger is a traditional remedy, used for the treatment of numerous dis- 
eases for years (11). It has a powerful effect on scavenging ROS, free radicals, peroxides, and various other damaging oxidants (12-15). Also, it shows anti-inflammatory (16) and antidiareal properties $(17,18)$, reduces radiation-induced stress (19, 20), and exerts anticancer (21-23), antiemetic (24$26)$, and lipolytic effects $(27,28)$.

\section{Objectives}

In this study, we decided to use an experimental rat model to evaluate if the most important constituent of ginger, zingerone, can reduce the severity of the dangerous side effects of methotrexate, i.e., hepatotoxicity, as one of the commonly used prescribed drugs. Regarding the increasing popularity of natural products for use as drugs, if it works, ginger can be a potential natural treatment for liver injury in patients who take MTX on a chronic basis.

\section{Methods}

\subsection{Chemicals}

All the chemicals were obtained from Sigma (St Louis, MO, USA), including zingerone, MTX, 5,5-dithiobis (2nitrobenzoic acid) (DTNB), thiobarbituric acid (TBA), Bradford reagent, trichloroacetic acid (TCA), GSH, and bovine serum albumin (BSA).

\subsection{Animals and Study Design}

The Central Animal House of Ahvaz Jundishapur University of Medical Sciences supplied 37 adult male Wistar rats weighing 180 - 220 grams. They were kept in standard rat cages under the room temperature of $24-26^{\circ} \mathrm{C}$ and a 12$\mathrm{h}$ light/dark cycle and had free access to standard rat food and water. We divided them into five groups of seven animals. Before starting the treatment, they were left for seven days to acclimatize to the new environment. The groups included:

1. Control group: Receiving normal saline (N/S), once daily, by gavage, for 10 days, and N/S intraperitoneally(i.p.), a single dose on the ninth day.

2. Methotrexate group (MTX): Receiving normal saline, once daily, by gavage, for 10 days, and MTX intraperitoneally (i.p.), a single dose (20 $\mathrm{mg} / \mathrm{kg}$ ) on the ninth day.

3. Zingerone 25 (ZG25): Receiving zingerone suspension in $\mathrm{N} / \mathrm{S}$ ( $25 \mathrm{mg} / \mathrm{kg}$ ), once daily, by gavage, for 10 days, and MTX intraperitoneally (i.p.), a single dose (20 mg/kg) on the ninth day,

4. Zingerone 50 (ZG50): Receiving zingerone suspension in N/S (50 mg/kg), once daily, by gavage, for 10 days, and MTX intraperitoneally (i.p.), a single dose (20 mg/kg), on the ninth day.

5. Zingerone 100 (ZG100): Receiving zingerone suspension in $\mathrm{N} / \mathrm{S}$ (100 mg/kg), once daily, by gavage, for 10 days, and MTX intraperitoneally (i.p.), a single dose (20 mg/kg) on the ninth day.

The protocols used in this study were approved by the Animal Care and Use Committee of Ahvaz Jundishapur University of Medical Sciences (Ethics code: IR.AJUMS.ABHC.REC.1398.034). The authors confirm that no changes were made to the initial protocols.

\subsection{Sample Collection and Preparation}

After 24 hours of the last administration, rats received a dose of ketamine and xylazine $(60 / 6 \mathrm{mg} / \mathrm{kg}$, i.p.) for the induction of anesthesia, and 2 cc of whole blood was taken from the jugular vein and centrifuged for 15 minutes at $3,000 \mathrm{rpm}$. The serum was isolated and stored at $-20^{\circ} \mathrm{C}$ until further analysis for ALT, AST, and ALP. Then, liver tissues were harvested. Some of the liver tissue, which was needed for histological studies, was fixed in phosphate-buffered formalin (10\%). Another part of the liver tissue underwent homogenization with the chilled Tris-HCl buffer $(0.1 \mathrm{M}, \mathrm{pH}$ 7.4) and the supernatant was kept at $-80^{\circ} \mathrm{C}$ for assessing tissue protein concentrations by the Bradford method (29) using crystalline bovine serum albumin as standard, as well as for all tissue biochemical assays.

\subsection{Serum Biochemical Assays}

The activities of serum ALP, ALT, and AST were measured by colorimetric kits (Wiesbaden, Germany) using a spectrophotometer (UNICO Instruments C., Model 1200, USA).

\subsection{Tissue Biochemical Assays}

\subsubsection{Malondialdehyde (MDA)}

The MDA level was measured based on Aust's method (30). The tissue supernatant $(0.5 \mathrm{~mL})$ was added into TCA (1.5 mL; 10\%, w/v)-containing tubes. Afterward, tubes were centrifuged for 10 minutes at 3,400 rpm. Then, $1.5 \mathrm{~mL}$ of the supernatant was added to the tubes with TBA ( $2 \mathrm{ml}$; $0.67 \%$ $\mathrm{w} / \mathrm{v})$. The mixture was kept in boiling water for 30 minutes, and a pink solution was formed; then, the mixture was cooled down immediately. To measure absorbance at 532 nm, a spectrophotometer (UV-1650 PC; Shimadzu, Japan) was used, and the level of MDA ( $\mathrm{nmol} / \mathrm{mg}$ protein) was determined using a specific absorbance coefficient related to TBA-MDA.

\subsubsection{Reduced Glutathione (GSH)}

We assessed GSH based on the reaction with Ellman's reagent (DTNB) (31). For precipitating the tissue homogenate supernatant, $100 \mathrm{~mL}$ of TCA (25\%) was used. Then, by using a centrifuge, the precipitate was removed, and $0.1 \mathrm{~mL}$ of the supernatant was blended with $2 \mathrm{~mL}$ of DTNB (0.5 mM). Absorbance at $412 \mathrm{~nm}$ was measured by a UV-Vis spectrophotometer (Shimadzu, Japan). Final results extrapolated the GSH content from the standard curve (nmol/mg protein). 


\subsubsection{Protein Carbonyl (PC)}

In the assay, $500 \mathrm{~mL}$ of $\mathrm{DNPH}(0.1 \%)$ in $2 \mathrm{~N} \mathrm{HCl}$ was mixed with $500 \mathrm{~mL}$ of the supernatant and kept in dark for one hour. The product was mixed with TCA (20\%) and then centrifuged. The supernatant was thrown away. The pellets were washed out with $0.5 \mathrm{~mL}$ of ethanol-ethyl acetate and were suspended in Tris-buffered 8M guanidine $\mathrm{HCl}(1000$ $\mathrm{mL}$ ). A UV-Vis spectrophotometer (UV-1650 PC, Shimadzu, Japan) was used to measure absorbance at $370 \mathrm{~nm}$ (nmol of carbonyl/mg protein) (32).

3.5.4. Superoxide Dismutase (SOD), Nitric Oxide (NO), Glutathione Peroxidase (GPX), and Catalase (CAT)

The level of NO (nmol/mg protein) and the activities of SOD, GPx, and CAT enzymes (units/mg of protein) in the liver were measured by specific kits (ZellBio, Germany), following the manufacturer's instructions.

\subsubsection{Tumor Necrosis Factor- $\alpha$ (TNF-a) and Interleukin $1 \beta$ (IL-} $1 \beta)$

Rat TNF- $\alpha$ and IL-1 $\beta$ ELISA kits (IBL, USA) were used following the manufacturer's instructions for measuring TNF- $\alpha$ and IL-1 $\beta$ tissue levels (pg/mg protein).

\subsection{Histopathological Examination}

After at least 24 hours, the samples were pulled out from $10 \%$ formalin, which was used for fixing the tissue. The dehydration of liver tissue was accomplished by embedding in paraffin and a sequence of ethanol solutions. The tissues were cut into $5 \mu \mathrm{m}$ sections and stained with Hematoxylin \& Eosin (H\&E) stain. A light microscope (OLYMPUS, Japan) was used for observing the slides blindly. The congestion of RBC, inflammatory cell infiltration, fat deposit, and pyknosis were assessed as inflammation indices. Semi-quantitative analysis of these indices was accomplished based on the following scoring system: (1) $0=$ normal tissue; (2) 1 = mild hepatic injury; (3) 2 = moderate hepatic injury; and (4) 3 = severe hepatic injury. The total score was calculated by obtaining the average of all scores in each group.

\subsection{Statistical Analysis}

The Graph Pad Prism 5.0 (San Diego, CA) software was used for data analysis. We used one-way ANOVA and Tukey's post hoc tests for multiple comparisons. A p value of $<0.05$ was considered significant, and the results were reported as means \pm SD.

\section{Results}

\subsection{Zingerone Effect on Serum ALP, AST, and ALT}

Serum ALP, AST, and ALT were significantly higher in MTX-intoxicated rats than in the control group $(\mathrm{P}<0.05)$.
The administration of zingerone (50 and $100 \mathrm{mg} / \mathrm{kg}$ ) significantly lowered the serum levels of ALT and AST in rats with hepatotoxicity $(\mathrm{P}<0.05)$. Besides, ALP was lowered significantly only by zingerone $(100 \mathrm{mg} / \mathrm{kg}, \mathrm{P}<0.05)$ (Figure 1 ).

\subsection{Zingerone Effect on MDA, NO, and PC in Liver Tissue}

The liver tissue levels of MDA, NO, and PC were significantly higher in rats intoxicated with MTX than in the control group ( $\mathrm{P}<0.05)$. The MDA tissue levels were lowered significantly by the administration of zingerone (50 and $100 \mathrm{mg} / \mathrm{kg}, \mathrm{P}<0.05)$. Besides, NO tissue levels could significantly be lowered only by zingerone $(100 \mathrm{mg} / \mathrm{kg}, \mathrm{P}<$ 0.05). But, PC tissue levels could be lowered by all doses of zingerone $(\mathrm{P}<0.05)$ (Figure 2 ).

\subsection{Zingerone Effect on Activity of SOD and CATEnzymes in Liver Tissue}

The SOD and CAT enzymes had significantly lower activity in MTX-intoxicated rats than in the control group ( $P$ $<0.05$ ). The SOD activity was accelerated significantly only by the administration of zingerone $100 \mathrm{mg} / \mathrm{kg}(\mathrm{P}<0.05)$. But, both doses of 50 and $100 \mathrm{mg} / \mathrm{kg}$ of zingerone could significantly increase the activity of CAT $(\mathrm{P}<0.05)$ (Figure 3 ).

\subsection{Zingerone Effect on GSH Content and Activity of GPX En- zyme in Liver Tissue}

The content of GSH and the activity of the GPX enzyme were significantly lower in rats intoxicated by MTX than in the control group $(\mathrm{P}<0.05)$. The GSH content was accelerated significantly by the administration of zingerone 50 and $100 \mathrm{mg} / \mathrm{kg}(\mathrm{P}<0.05)$. But, all doses of zingerone could significantly increase the activity of GPX $(\mathrm{P}<0.05)$ (Figure 4).

\subsection{Zingerone Effect on TNF- $\alpha$ and IL-1 $\beta$ in Liver Tissue}

Liver tissue levels of TNF- $\alpha$ and IL- $1 \beta$ were significantly higher in rats intoxicated by MTX than in the control group $(\mathrm{P}<0.05)$. The TNF- $\alpha$ tissue levels were lowered significantly by the administration of zingerone ( 50 and 100 $\mathrm{mg} / \mathrm{kg}, \mathrm{P}<0.05)$. But, IL-1 $\beta$ tissue levels could be lowered by all doses of zingerone $(\mathrm{P}<0.05)$ (Figure 5$)$.

\subsection{Zingerone Effect on Histopathological Features of Liver Tis-} sue

The histopathological exam of liver tissue in the control group revealed a normal structure of cells, an intact cytoplasm, a well-defined nucleus, portal tracts, and central veins (Figure 6A and Table 1). The congestion of RBCs (C), infiltration of inflammatory cells, severe cellular damage, fat deposition, and nuclear pyknosis (P) were seen in the group treated with MTX (Figure 6B and Table 1). 

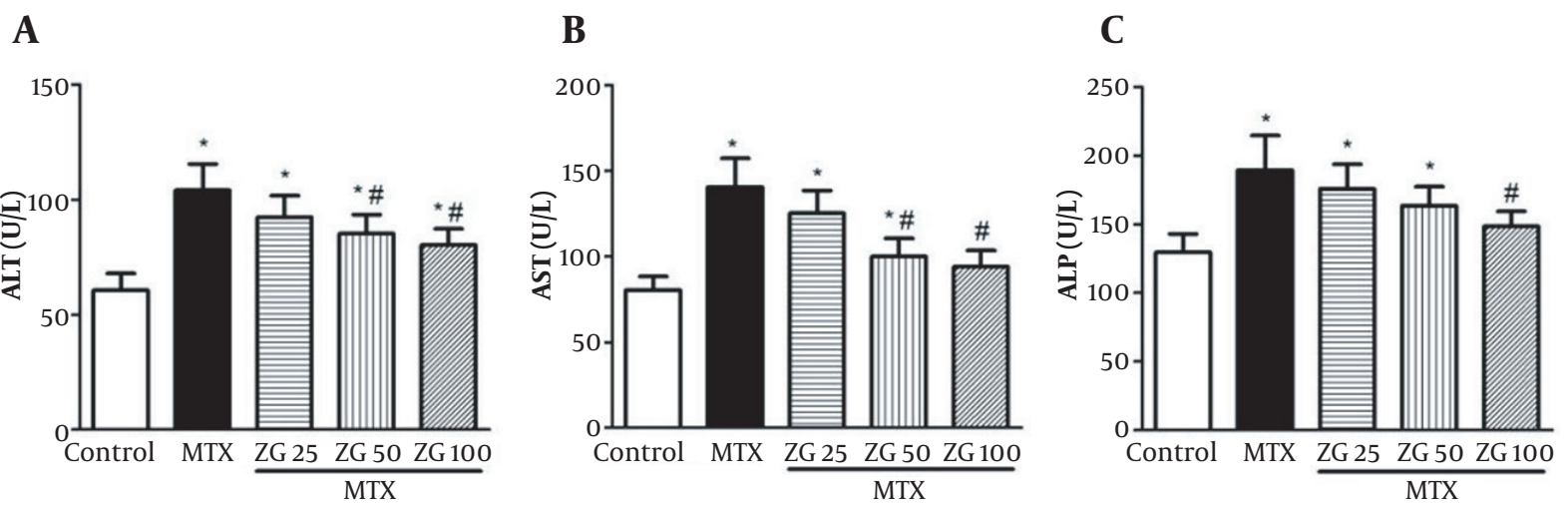

Figure 1. Effect of zingerone on serum enzymes of ALT, AST, and ALP in rats treated with MTX (mean \pm SD; $n=7$ ) [ZG, zingerone; MTX: methotrexate; * Significant difference with the control group $(\mathrm{P}<0.05)$; \# Significant difference with the MTX group $(\mathrm{P}<0.05)]$.
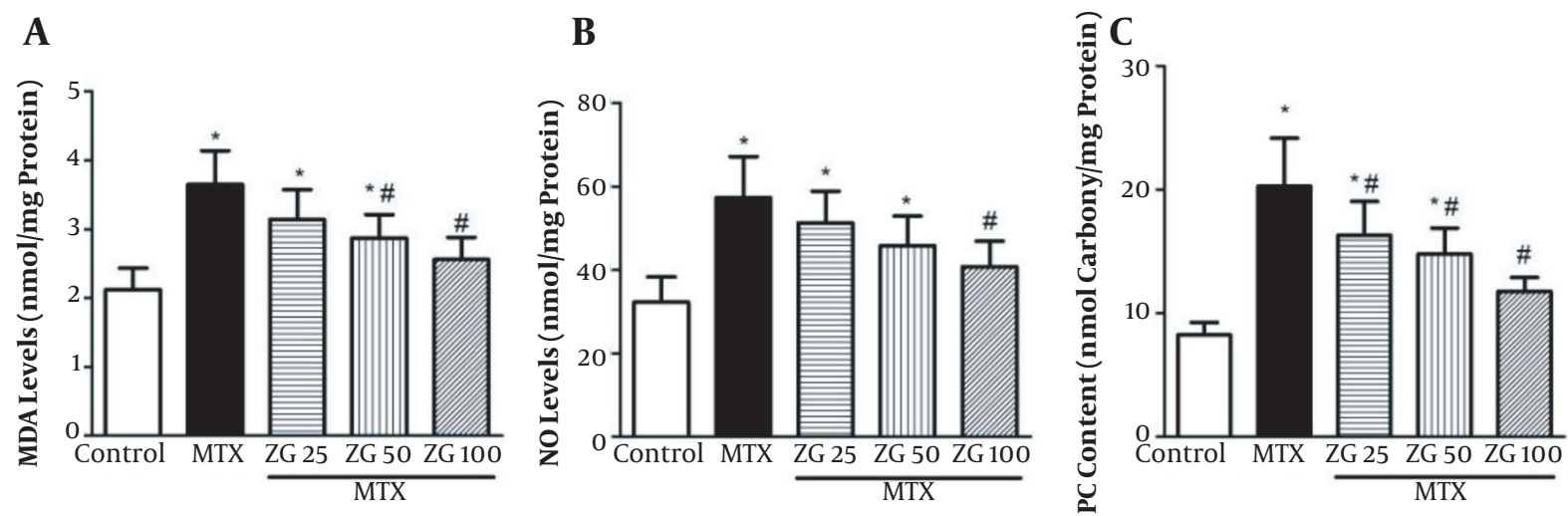

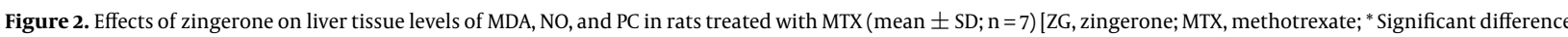
with the control group $(\mathrm{P}<0.05)$; \# Significant difference with the MTX group $(\mathrm{P}<0.05)]$.

Zingerone with all doses significantly decreased the abovementioned distractive changes, when compared with the MTX group (Figure 6C - E, respectively, and Table 1), except for one feature (congestion of RBC in the ZG25 group).

\section{Discussion}

Methotrexate (MTX) is one of the medicines on the World Health Organization's list of essential medicines. The MTX chronic administration even at very low doses is toxic to the liver, kidney, respiratory, reproductive, and hematopoietic systems. The liver is the organ, which is affected most by this drug (1). Using natural products for treating diseases is now increasing due to lifestyle changes. People all around the world have become more alert about health and nutrition and prefer to take natural products instead of synthetic drugs, due to their fewer side effects (11). In this study, we evaluated the role of zingerone (one of the main constituents of the natural substance, ginger) on MTX-induced liver injury in a rat model, from diverse points of view, including redox system, inflammation, and liver enzymes. Finally, we did histopathological examinations to see if they confirm our results.

Injury to the liver (acute or chronic) results in an increment in serum concentrations of liver aminotransferases (AST and ALT). Besides, Alkaline Phosphatase (ALP) levels can mostly be elevated by liver and bone diseases (33). The present study showed that the administration of zingerone could decrease ALT, AST, and ALP by at least one dose of zingerone significantly. Amin et al. and Mir et al. confirm our study by showing the protective effect of zingerone on lead- (8) and cyclophosphamide (34)induced hepatoxicity, respectively, regarding liver function markers.

The imbalance between reactive oxygen and nitrogen species (RONS) production and antioxidant defense 
A

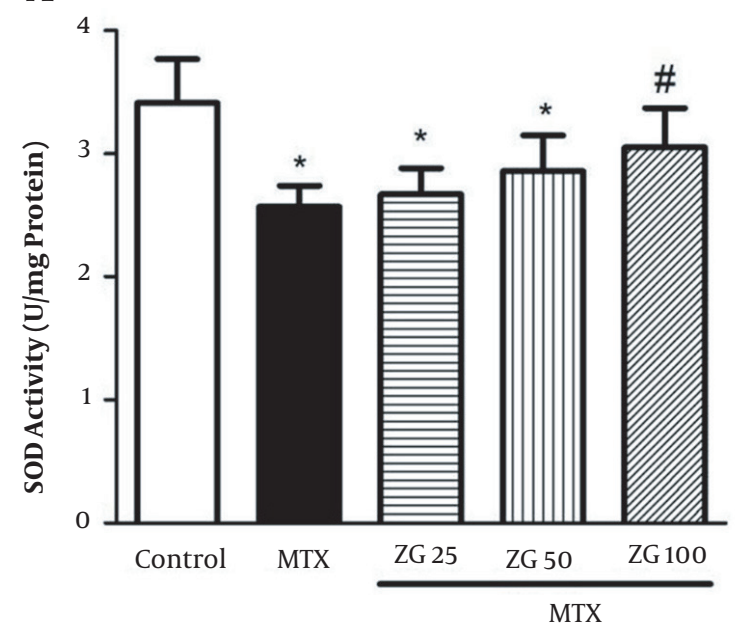

B

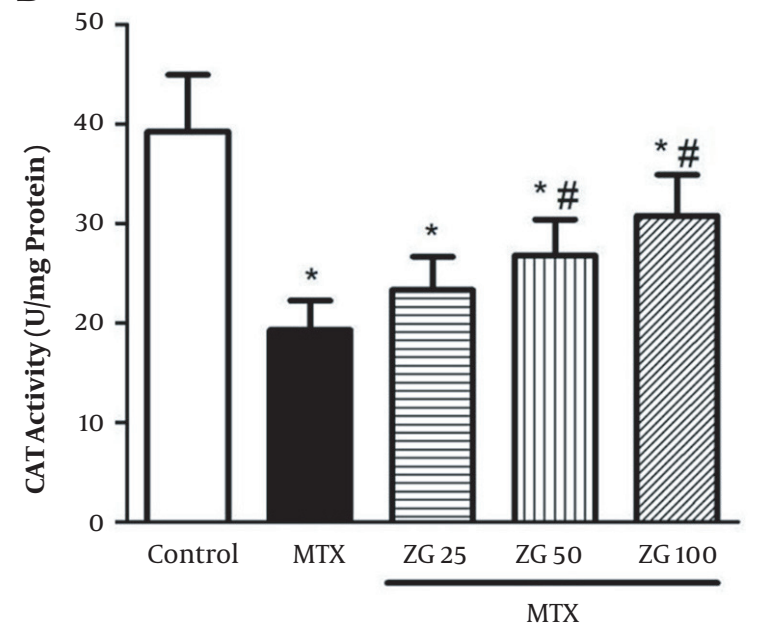

Figure 3. Effects of zingerone on the activity of SOD and CAT enzymes in liver tissue of rats treated with MTX (mean \pm SD; $n=7$ ) [ZG, zingerone; MTX, methotrexate; * Significant difference with the control group $(\mathrm{P}<0.05)$; \# Significant difference with the MTX group $(\mathrm{P}<0.05)]$.

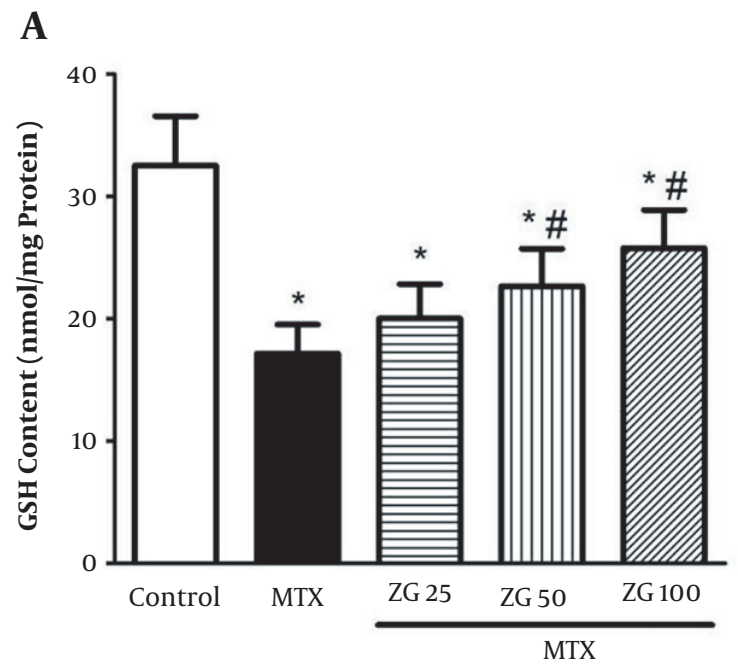

B

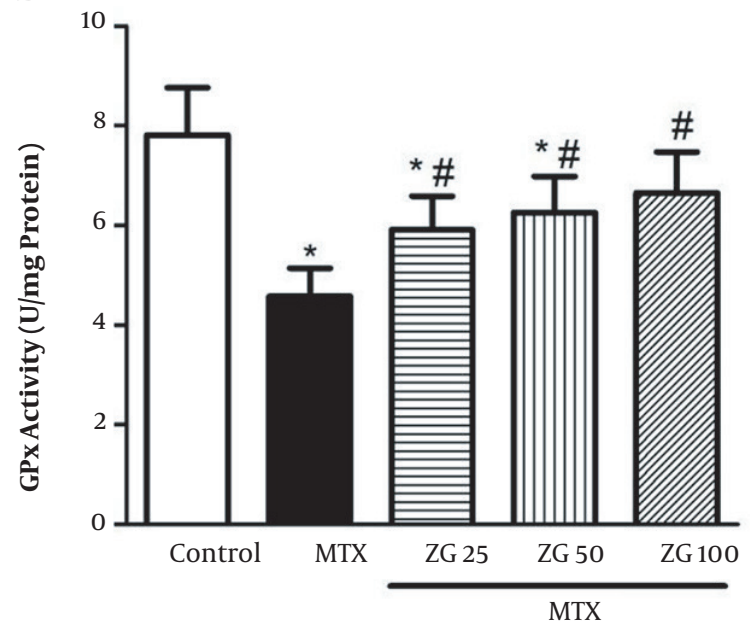

Figure 4. Effects of zingerone on the content of GSH and activity of GPX enzyme in liver tissue of rats treated with MTX (mean \pm SD; $n=7$ ) [ZG, zingerone; MTX, methotrexate; *Significant difference with the control group $(\mathrm{P}<0.05)$; \# Significant difference with the MTX group $(\mathrm{P}<0.05)$.

systems can result in oxidative stress. Besides, RONS is the result of many endogenous and exogenous processes (35). Enzymes such as catalase (CAT), superoxide dismutase (SOD), and glutathione peroxidase (GPx) are the main cellular antioxidant defensive systems that can protect cells against ROS-induced damage (36).

Lipids are the most important targets of oxidative stress. Lipid oxidation gives rise to the production of malondialdehyde (MDA), which has potentially mutagenic ef- fects (37). This study demonstrated that zingerone (50 and $100 \mathrm{mg}$ ) could decrease the main product of lipid peroxidation (MDA), showing its ability to defeat oxidative damage in MTX-induced hepatotoxicity. Mir et al. also showed that zingerone could attenuate MDA elevation induced by cyclophosphamide-induced liver injury, which confirms our results (34).

Although nitric oxide (NO) plays an important role in several vital physiological functions (38), it is also a poi- 
A

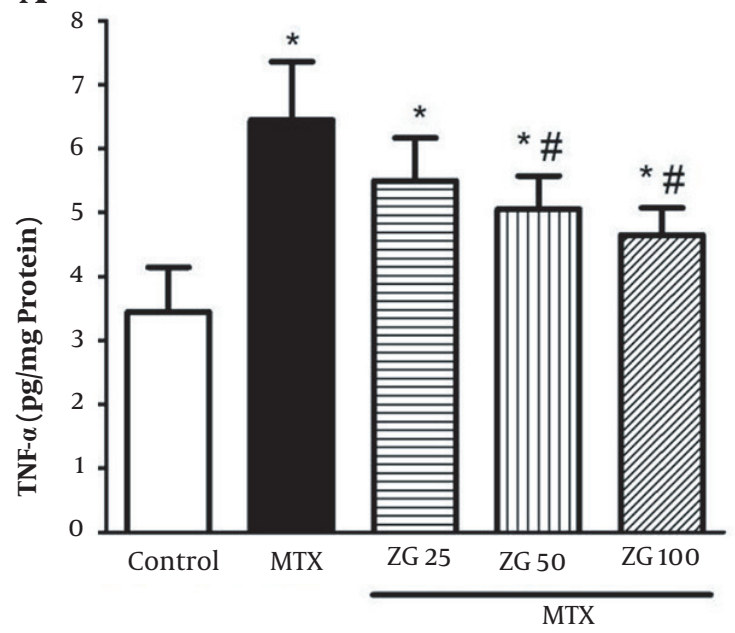

B

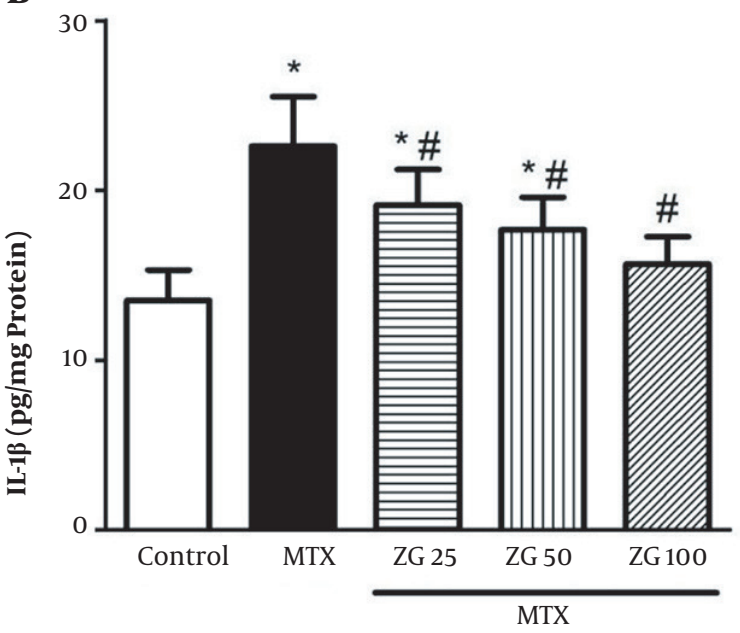

Figure 5. Effects of zingerone on liver tissue levels of TNF- $\alpha$ and IL-1 $\beta$ in rats treated with MTX (mean \pm SD; $n=7$ ) [ZG, zingerone; MTX, methotrexate; * Significant difference with the control group $(\mathrm{P}<0.05)$; \# Significant difference with the MTX group $(\mathrm{P}<0.05)]$.

Table 1. Histopathological Changes in Rat Liver Sections (Semi-quantitative, H\&E Staining)

\begin{tabular}{|c|c|c|c|c|c|}
\hline \multirow{2}{*}{ Histological Criteria } & \multicolumn{5}{|c|}{ Groups } \\
\hline & Control & MTX & ZG25 & ZG50 & ZG100 \\
\hline Congestion of RBC & $0.3 \pm 0.1$ & $2.6 \pm 0.2^{\mathrm{a}}$ & $2.3 \pm 0.1^{\mathrm{a}}$ & $1.3 \pm 0.3^{a, b}$ & $0.5 \pm 0.3^{b}$ \\
\hline $\begin{array}{l}\text { Infiltration of } \\
\text { inflammatory cells }\end{array}$ & $0.4 \pm 0.2$ & $2.5 \pm 0.3^{a}$ & $2.1 \pm 0.1^{\mathrm{a}, \mathrm{b}}$ & $1.0 \pm 0.2^{a, b}$ & $0.8 \pm 0.1^{\mathrm{a}, \mathrm{b}}$ \\
\hline Fat deposit (\%) & $3.8 \pm 0.5$ & $28.3 \pm 3.7^{\mathrm{a}}$ & $25.1 \pm 2.1^{\mathrm{a}, \mathrm{b}}$ & $11.9 \pm 1.1^{\mathrm{a}, \mathrm{b}}$ & $6.9 \pm 0.8^{b}$ \\
\hline Pyknosis (\%) & $1.8 \pm 0.2$ & $30.5 \pm 4.5^{\mathrm{a}}$ & $23.3 \pm 3.2^{a, b}$ & $16.1 \pm 2.1^{\mathrm{a}, \mathrm{b}}$ & $4.1 \pm 1.6^{b}$ \\
\hline
\end{tabular}

${ }^{a}$ Significant difference with the control group, $\mathrm{P}<0.05$.

${ }^{\mathrm{b}}$ Significant difference with the MTX group, $\mathrm{P}<0.05$.

sonous, highly reactive, short-lived, and unstable free radical gas (39), which can induce apoptotic cell death in neuronal cells $(7,34)$. When NO reacts with superoxide radicals, it yields peroxynitrite, which can cause membrane peroxidation, DNA damage, and GSH content depletion (34). The current study showed that zingerone $(100 \mathrm{mg} / \mathrm{kg}$ ) could significantly decrease the level of liver tissue NO in MTX-induced hepatic injury. Wei et al. declared that ROS is probably involved in a series of events that result in cell injury by NO (7). Therefore, we can conclude that zingerone shows a protective effect against cell apoptosis and possibly performs this protection via decreasing ROS in the liver. Mir et al. also showed a result parallel to our results; they showed the protective effects of zingerone regarding reduced nitrite production in cyclophosphamide-induced hepatic injury (34).

Moreover, RONS can oxidize proteins and give rise to the production of reactive molecules known as protein carbonyl (PC). A reliable indicator of protein oxidation is the quantity of PC in blood and tissues (40). This study showed that zingerone with all doses used could decrease the elevated tissue levels of PC in the liver of MTX-treated rats. In another study, Hosseinzadeh et al. showed that zingerone could decrease the content of PC in renal tissue in gentamicin-induced nephrotoxicity in rats (41). As protein carbonyl is an indicator of the existence of free radicals (42), it can be concluded that zingerone has an antioxidant property.

Superoxide dismutase (SOD) is an important antioxidant defense system in nearly all living cells exposed to oxygen (43). Besides, SOD can halt the damaging potential of the superoxide onion. Also, SOD catalyzes the dismutation of superoxide to oxygen plus hydrogen peroxide $\left(\mathrm{H}_{2} \mathrm{O}_{2}\right)(44)$. Hydrogen peroxide is also detrimental and can be degraded by catalase (43). In the current study, we proved that zingerone $(100 \mathrm{mg} / \mathrm{kg}$ ) could increase the activity of both SOD and CAT in the liver of MTX-affected rates. Amin et al. and Mir et al. confirmed our results about the 

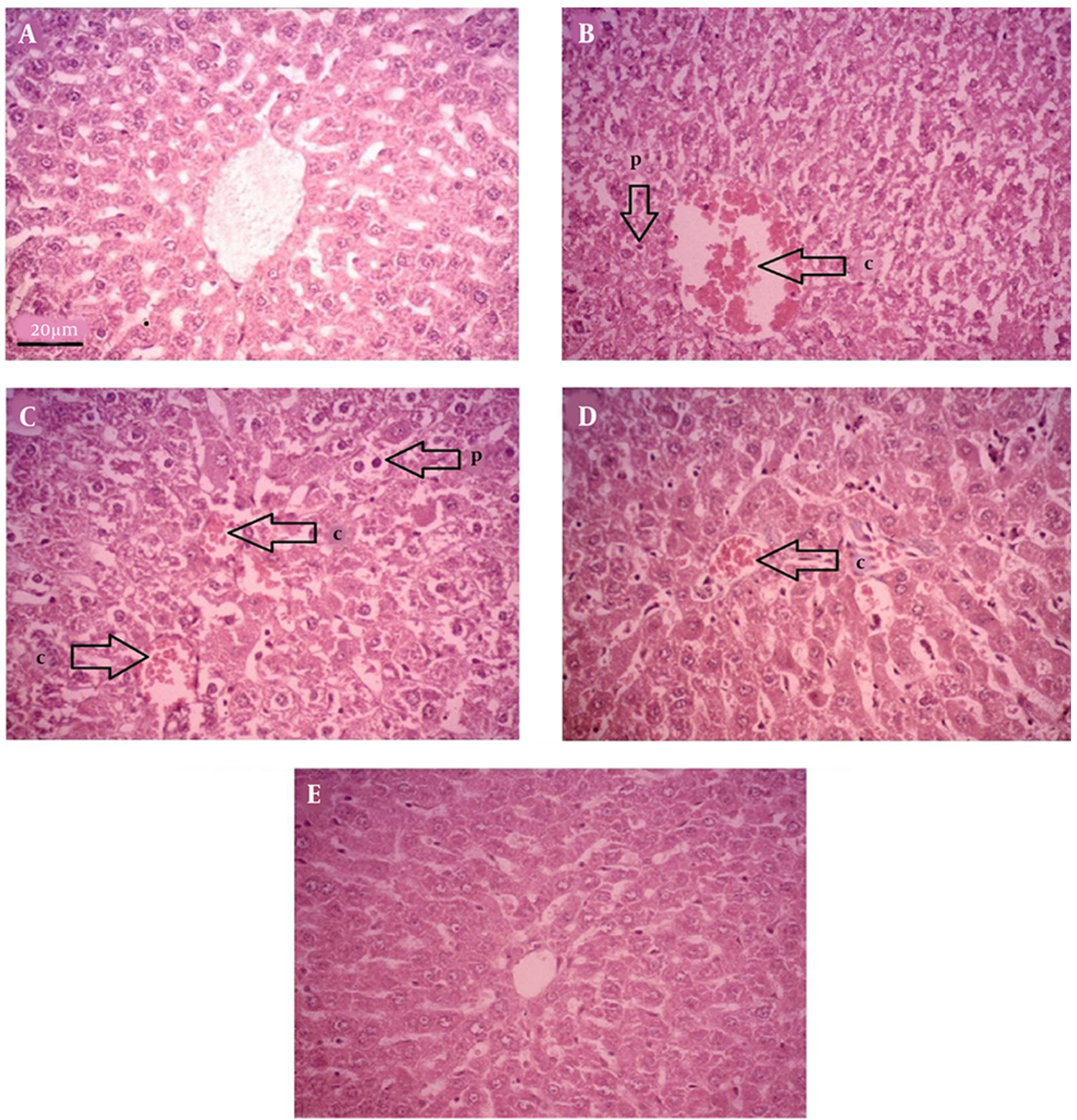

Figure 6. Histopathological observations showing the effects of zingerone on rat liver tissue. (sections stained with Hematoxylin \& Eosin, magnification X 200) [C, congestion of RBC; P, pyknosis; A, control; B, MTX; C, ZG25; D, ZG50; E, ZG10o].

increasing activity of CAT and SOD by using zingerone (8, 34).

Reduced glutathione (GSH) is at the center of one of the most important antioxidant systems. It is capable of scavenging RONS and acting as a cofactor for an antioxidant enzyme, glutathione peroxidases (GPX) (45). In this study, we proved that these two important agents in the redox system could be increased by using zingerone (50 and 100 $\mathrm{mg} / \mathrm{kg}$ ) in rats with MTX-induced hepatic injury. Mir et al. showed results parallel to our study results regarding the increments of both GPX activity and GSH liver content by zingerone (34). Amin et al.'s study, parallel with our study, showed the increased activity of GPX in hepatic injury by administering zingerone (8). 
This study showed that zingerone could decrease proinflammatory cytokines (IL- $1 \beta$ and TNF- $\alpha$ ). As known, ROS production leads to neutrophil infiltration and proinflammatory cytokine release, and this can result in apoptosis, cell damage, and death (6). Thus, it is concluded that zingerone can protect hepatic injury via decreasing inflammation and ROS features. Knuckler et al. also showed similar results; they declared that zingerone could decrease these cytokines that are responsible for inflammation and apoptosis in vancomycin-induced hepatoxicity (46).

The current study showed a great improvement in MTX-induced histopathological changes in liver tissue after zingerone administration. Zingerone, at least at two doses, could reduce all features assessed for hepatic cell damage. Amin et al. also stated a significant positive change in hepatic and renal histopathology by zingerone, which confirms this study.

\subsection{Conclusion}

Zingerone can improve hepatic injury induced by methotrexate in rats regarding the redox system features, inflammation, and histological changes. This can make humans hopeful for using Ginger in the future for attenuating the hepatic side effects of MTX when used chronically.

\section{Footnotes}

Authors' Contribution: Alireza Malayeri and Narjes Zaeemzadeh convinced and designed the study. Mehdi Goudarzi and Ali Nesari performed the study and analyses, collected the data, and prepared all figures (other than Figure 6). Zahra Basir performed pathology staining, completed the relevant data, and prepared Figure 6 and the sole table. Narjes Zaeemzadeh and Alireza Malayeri wrote the whole manuscript.

Conflict of Interests: The authors declare no financial and non-financial competing interests.

Ethical Approval: The protocols used in this study were approved by the "Animal Care and Use Committee" of Ahvaz Jundishapur University of Medical Sciences (ethics code: IR.AJUMS.ABHC.REC.1398.034).

Funding/Support: This project is financially supported by Ahvaz Jundishapur University of Medical Sciences under the registration number MPRC-9813.

\section{References}

1. Montasser AOS, Saleh H, Ahmed-Farid OA, Saad A, Marie MS. Protective effects of Balanites aegyptiaca extract, Melatonin and Ursodeoxycholic acid against hepatotoxicity induced by Methotrexate in male rats. Asian Pac J Trop Med. 2017;10(6):557-65. doi: 10.1016/j.apjtm.2017.06.003. [PubMed: 28756919].
2. Herfarth HH. Methotrexate for Inflammatory Bowel Diseases - New Developments. Dig Dis. 2016;34(1-2):140-6. doi: 10.1159/000443129. [PubMed: 26981630]. [PubMed Central: PMC4820247].

3. Mahmoud AM, Hussein OE, Hozayen WG, Abd El-Twab SM. Methotrexate hepatotoxicity is associated with oxidative stress, and down-regulation of PPARgamma and Nrf2: Protective effect of 18beta-Glycyrrhetinic acid. Chem Biol Interact. 2017;270:59-72. doi: 10.1016/j.cbi.2017.04.009. [PubMed: 28414158].

4. Al-Fatlawi AAY, Al-Shammari MMM. Rice bran phytic acid protects against methotrexate-induced oxidative stress and acute liver injury in rats. Kufa J Vet Sci. 2017;8(1).

5. Khafaga AF, El-Sayed YS. Spirulina ameliorates methotrexate hepatotoxicity via antioxidant, immune stimulation, and proinflammatory cytokines and apoptotic proteins modulation. Life Sci. 2018;196:9-17. doi:10.1016/j.lfs.2018.01.010. [PubMed: 29339102].

6. Cure E, Kirbas A, Tumkaya L, Cure MC, Kalkan Y, Yilmaz A, et al. Protective effect of infliximab on methotrexate-induced liver injury in rats: Unexpected drug interaction. J Cancer Res Ther. 2015;11(1):164-9. doi: 10.4103/0973-1482.140809. [PubMed: 25879356].

7. Wei T, Chen C, Hou J, Zhao B, Xin W, Mori A. The antioxidant EPC-K1 attenuates NO-induced mitochondrial dysfunction, lipid peroxidation and apoptosis in cerebellar granule cells. Toxicology.1999;134(2-3):11726. doi: 10.1016/s0300-483x(99)00030-x. [PubMed: 10403631].

8. Amin I, Hussain I, Rehman MU, Mir BA, Ganaie SA, Ahmad SB, et al. Zingerone prevents lead-induced toxicity in liver and kidney tissues by regulating the oxidative damage in Wistar rats. J Food Biochem. 2021;45(3). e13241. doi: 10.1111/jfbc.13241. [PubMed: 32515504].

9. Park EJ, Pezzuto JM. Botanicals in cancer chemoprevention. Cancer Metastasis Rev. 2002;21(3-4):231-55. doi: 10.1023/a:1021254725842. [PubMed: 12549763].

10. Zhang YX, Li JS, Chen LH, Peng WW, Cai BC. Simultaneous determination of five gingerols in raw and processed ginger by HPLC. Chin Pharm J. 2012;47(6):471-4.

11. Ahmad B, Rehman MU, Amin I, Arif A, Rasool S, Bhat SA, et al. A Review on Pharmacological Properties of Zingerone (4-(4Hydroxy-3-methoxyphenyl)-2-butanone). ScientificWorldJournal. 2015;2015:816364. doi: 10.1155/2015/816364. [PubMed: 26106644]. [PubMed Central: PMC4461790].

12. Rajan I, Narayanan N, Rabindran R, Jayasree PR, Manish Kumar PR. Zingerone protects against stannous chloride-induced and hydrogen peroxide-induced oxidative DNA damage in vitro. Biol Trace Elem Res. 2013;155(3):455-9. doi: 10.1007/s12011-013-9801-x. [PubMed: 24006104].

13. Banji D, Banji OJ, Pavani B, Kranthi Kumar C, Annamalai AR. Zingerone regulates intestinal transit, attenuates behavioral and oxidative perturbations in irritable bowel disorder in rats. Phytomedicine. 2014;21(4):423-9. doi: 10.1016/j.phymed.2013.10.007. [PubMed: 24262066].

14. Vaibhav K, Shrivastava P, Tabassum R, Khan A, Javed H, Ahmed ME, et al. Delayed administration of zingerone mitigates the behavioral and histological alteration via repression of oxidative stress and intrinsic programmed cell death in focal transient ischemic rats. Pharmacol Biochem Behav. 2013;113:53-62. doi: 10.1016/j.pbb.2013.10.008. [PubMed: 24141173].

15. Kabuto H, Yamanushi TT. Effects of zingerone [4-(4-hydroxy3-methoxyphenyl)-2-butanone] and eugenol [2-methoxy-4(2-propenyl)phenol] on the pathological progress in the 6hydroxydopamine-induced Parkinson's disease mouse model. Neurochem Res. 2011;36(12):2244-9. doi: 10.1007/s11064-011-0548-5. [PubMed: 21769642].

16. Kumar L, Chhibber S, Harjai K. Hepatoprotective effect of zingerone (4-(4-hydroxy-3-methoxyphenyl) butan-2-one) in lipopolysaccharide induced liver injury mouse model through down regulation of inflammatory mediators. Int JPharmacogn Phytochem Res. 2014;6(2):30814.

17. Chen JC, Huang LJ, Wu SL, Kuo SC, Ho TY, Hsiang CY. Ginger and its bioactive component inhibit enterotoxigenic Escherichia coli heat-labile enterotoxin-induced diarrhea in mice. J Agric Food Chem. 2007;55(21):8390-7. doi: 10.1021/jf071460f. [PubMed: 17880155]. 
18. Iwami M, Shiina T, Hirayama H, Shima T, Takewaki T, Shimizu Y. Inhibitory effects of zingerone, a pungent component of Zingiber officinale Roscoe, on colonic motility in rats. J Nat Med. 2011;65(1):89-94. doi:10.1007/s11418-010-0463-0. [PubMed: 20799069].

19. Rao BN, Rao BS, Aithal BK, Kumar MR. Radiomodifying and anticlastogenic effect of Zingerone on Swiss albino mice exposed to whole body gamma radiation. Mutat Res. 2009;677(1-2):33-41. doi: 10.1016/j.mrgentox.2009.05.004. [PubMed: 19463966].

20. Motohashi N, Ashihara Y, Yamagami C, Saito Y. Antimutagenic effects of dehydrozingerone and its analogs on UV-induced mutagenesis in Escherichia coli. Mutat Res. 1997;377(1):17-25. doi: 10.1016/s00275107(97)00054-7. [PubMed: 9219575].

21. Aggarwal BB, Shishodia S. Molecular targets of dietary agents for prevention and therapy of cancer. Biochem Pharmacol. 2006;71(10):1397421. doi: 10.1016/j.bcp.2006.02.009. [PubMed: 16563357].

22. Surh YJ. Cancer chemoprevention with dietary phytochemicals. Nat Rev Cancer. 2003;3(10):768-80. doi: 10.1038/nrc1189. [PubMed: 14570043].

23. Vinothkumar R, Vinothkumar R, Sudha M, Nalini N. Chemopreventive effect of zingerone against colon carcinogenesis induced by 1,2dimethylhydrazine in rats. Eur J Cancer Prev. 2014;23(5):361-71. doi: 10.1097/CEJ.ob013e32836473ac. [PubMed: 23903760].

24. Pillai AK, Sharma KK, Gupta YK, Bakhshi S. Anti-emetic effect of ginger powder versus placebo as an add-on therapy in children and young adults receiving high emetogenic chemotherapy. Pediatr Blood Cancer. 2011;56(2):234-8. doi: 10.1002/pbc.22778. [PubMed: 20842754].

25. Ryan JL, Heckler CE, Roscoe JA, Dakhil SR, Kirshner J, Flynn PJ, et al. Ginger (Zingiber officinale) reduces acute chemotherapyinduced nausea: A URCC CCOP study of 576 patients. Support Care Cancer. 2012;20(7):1479-89. doi: 10.1007/s00520-011-1236-3. [PubMed: 21818642]. [PubMed Central: PMC3361530].

26. Jin Z, Lee G, Kim S, Park CS, Park YS, Jin YH. Ginger and its pungent constituents non-competitively inhibit serotonin currents on visceral afferent neurons. Korean J Physiol Pharmacol. 2014;18(2):14953. doi: 10.4196/kjpp.2014.18.2.149. [PubMed: 24757377]. [PubMed Central: PMC3994302].

27. Han LK, Morimoto C, Zheng YN, Li W, Asami E, Okuda H, et al. [Effects of zingerone on fat storage in ovariectomized rats]. Yakugaku Zasshi. 2008;128(8):1195-201. Japanese. doi: 10.1248/yakushi.128.1195. [PubMed: 18670185].

28. Thunchomnang K, Lawa K, Mangkhalathon A, Saenubol P, Rattanakiat $S$, Pulbutr P, editors. Lipolytic effects of zingerone in isolated rat adipocytes. 4th Annual Northeast Pharmacy Research Conference. 2012; Khon Kaen, Thailand. 2012.

29. Bradford MM. A rapid and sensitive method for the quantitation of microgram quantities of protein utilizing the principle of protein-dye binding. Anal Biochem. 1976;72:248-54. doi: 10.1006/abio.1976.9999. [PubMed: 942051].

30. Buege JA, Aust SD. [30] Microsomal lipid peroxidation. In: Fleischer S, Packer L, editors. Methods in Enzymology. 52. Massachusetts, USA: Academic Press;1978. p. 302-10. doi:10.1016/s0076-6879(78)52032-6.

31. Ellman GL. Tissue sulfhydryl groups. Arch Biochem Biophys. 1959;82(1):70-7. doi: 10.1016/0003-9861(59)90090-6. [PubMed: 13650640].

32. Goudarzi M, Kalantari H, Rezaei M. Glyoxal toxicity in isolated rat liver mitochondria. Hum Exp Toxicol. 2018;37(5):532-9. doi: 10.1177/0960327117715900. [PubMed: 28639457].
33. Giannini EG, Testa R, Savarino V. Liver enzyme alteration: A guide for clinicians. CMAJ. 2005;172(3):367-79. doi: 10.1503/cmaj.1040752. [PubMed: 15684121]. [PubMed Central: PMC545762].

34. Mir M, Mir B, Amin I, Rehman M, Razak R, Ali A, et al. Chemoprotective potential of zingerone (vanillyl acetone) in cyclophosphamideinduced hepatic toxicity. Pharmacogn Mag. 2018;14(57):434. doi: 10.4103/pm.pm_170_16.

35. Liguori I, Russo G, Curcio F, Bulli G, Aran L, Della-Morte D, et al. Oxidative stress, aging, and diseases. Clin Interv Aging. 2018;13:75772. doi: 10.2147/CIA.S158513. [PubMed: 29731617]. [PubMed Central: PMC5927356].

36. Pizzino G, Irrera N, Cucinotta M, Pallio G, Mannino F, Arcoraci V, et al. Oxidative Stress: Harms and Benefits for Human Health. Oxid Med Cell Longev. 2017;2017:8416763. doi: 10.1155/2017/8416763. [PubMed: 28819546]. [PubMed Central: PMC5551541].

37. Del Rio D, Stewart AJ, Pellegrini N. A review of recent studies on malondialdehyde as toxic molecule and biological marker of oxidative stress. Nutr Metab Cardiovasc Dis. 2005;15(4):316-28. doi: 10.1016/j.numecd.2005.05.003. [PubMed: 16054557].

38. Pierini D, Bryan NS. Nitric oxide availability as a marker of oxidative stress. In: Armstrong D, editor. Advanced Protocols in Oxidative Stress III. 1208. New York, USA: Humana Press; 2015. p. 63-71. doi: 10.1007/9781-4939-1441-8_5.

39. Wei T, Chen C, Hou J, Xin W, Mori A. Nitric oxide induces oxidative stress and apoptosis in neuronal cells. Biochim Biophys Acta. 2000;1498(1):72-9. doi: 10.1016/s0167-4889(00)00078-1. [PubMed: 11042352].

40. Fernando N, Wickremesinghe S, Niloofa R, Rodrigo C, Karunanayake L, de Silva HJ, et al. Protein Carbonyl as a Biomarker of Oxidative Stress in Severe Leptospirosis, and Its Usefulness in Differentiating Leptospirosis from Dengue Infections. PLoS One. 2016;11(6). e0156085. doi: 10.1371/journal.pone.0156085. [PubMed: 27280281]. [PubMed Central: PMC4900524].

41. Hosseinzadeh A, Goudarzi M, Karimi MY, Khorsandi L, Mehrzadi $S$, Mombeini MA. Zingerone ameliorates gentamicin-induced nephrotoxicity in rats. Comp Clin Path. 2020;29(5):971-80. doi: 10.1007/s00580-020-03129-5.

42. Archana AK, Maheswari R. Zingerone Ameliorates Free Radical Scavengers and Lipid Profile of Wistar Albino Rats. Int J Pharm Sci Res. 2016;7(6):254-60.

43. Hayyan M, Hashim MA, AlNashef IM. Superoxide Ion: Generation and Chemical Implications. Chem Rev. 2016;116(5):3029-85. doi: 10.1021/acs.chemrev.5b00407. [PubMed: 26875845].

44. Okado-Matsumoto A, Fridovich I. Subcellular distribution of superoxide dismutases (SOD) in rat liver: Cu,Zn-SOD in mitochondria. J Biol Chem. 2001;276(42):38388-93. doi: 10.1074/jbc.M105395200. [PubMed: 11507097].

45. Couto N, Wood J, Barber J. The role of glutathione reductase and related enzymes on cellular redox homoeostasis network. Free Radic Biol Med. 2016;95:27-42. doi: 10.1016/j.freeradbiomed.2016.02.028. [PubMed: 26923386].

46. Kucukler S, Darendelioglu E, Caglayan C, Ayna A, Yildirim S, Kandemir FM.Zingerone attenuates vancomycin-induced hepatotoxicity in rats through regulation of oxidative stress, inflammation and apoptosis. Life Sci. 2020;259:118382. doi: 10.1016/j.lfs.2020.118382. [PubMed: 32898532]. 